\title{
Antifungal Activity of Methylxanthines Based on Their Properties
}

\author{
Klára Kobetičová, ${ }^{\mathrm{a}, *}$ Jana Nábělková, ${ }^{\mathrm{b}}$ Kristýna Ďurišová, ${ }^{\mathrm{b}}$ Kristýna Šimůnková, ${ }^{\mathrm{c}}$ and \\ Robert Černý ${ }^{\mathrm{a}}$
}

\begin{abstract}
Wood materials for construction purposes can be attacked by various wood-destroying fungi. An ideal wood-preserving substance is supposed to be environment- and health-friendly. For this reason, the effects of the most relevant and non-toxic methylxanthines, such as caffeine and its metabolites theobromine and theophylline, on fungal growth, together with their degradability related to their properties were analyzed in this study. Agar tests with four wood-destroying fungal species (Serpula lacrymans, Coniophora puteana, Gleophyllum sepiarium, and Trametes versicolor) were performed after 28 days of substance exposure. Caffeine exhibited a $100 \%$ inhibitive effect on fungal growth, contrary to theobromine, which was not effective in that respect. Theophylline exhibited variable effects on the analyzed fungi. The analysis of degradability indicated the persistence of caffeine and theobromine, but theophylline was degraded up to $34 \%$. The relation of toxicity to chemical structure of studied methylxanthines indicated the dipole moment and lipophilicity as important parameters affecting the antifungal properties. Both caffeine and theophylline are suitable potential candidates for antifungal active substances.
\end{abstract}

Keywords: Methylxanthines; Caffeine; Theobromine; Theophylline; Fungi; Antifungal effects

Contact information: a: Department of Materials Engineering and Chemistry, Faculty of Civil Engineering, Czech Technical University in Prague, Thákurova 7/2077, 16629 Prague 6, Czech Republic; b: Department of Sanitary and Ecological Engineering, Faculty of Civil Engineering, Czech Technical University in Prague, Thákurova 7/2077, 16629 Prague 6, Czech Republic; c: Department of Wood Processing and Biomaterials, Faculty of Forestry and Wood Sciences, Czech University of Life Sciences, Kamýcká 129, Prague 165 00, Czech Republic; *Corresponding author: klara.kobeticova@fsv.cvut.cz

\section{INTRODUCTION}

Wood building materials are often attacked by wood-destroying pests. Therefore, various commercially available chemicals are commonly used for wood protection against biodegradation. However, some of these chemicals have been banned presently, and the production and use of some others will be discontinued in the near future.

Modern wood-preserving substances, to meet societal expectations, are supposed to be environment- and health-friendly. A suitable alternative to the previously used chemicals appears to be found in some natural extracts or individual substances with biocidal effects produced by plants for their own protection against pests (Islam et al. 2012; Singh and Singh 2012; Lee et al. 2018). The use of such natural herbal metabolites in wood preservation systems can reduce the amount of persistent artificial xenobiotics in the environment, while the active substance affects just the target organisms.

Caffeine is a commonly studied biocidal substance (Arora and Ohlan 1997; Lekounougou et al. 2007; Ashihara et al. 2008; Rahman et al. 2014). This type of 
methylxanthine is produced by the coffee tree. From the toxicological point of view, caffeine may paralyze or kill some insect species. It was also found that caffeine may be used as a neural poison against gastropods (Thomas 2013). The effect of caffeine on spiders was also confirmed (Hesselberg and Vollrath 2004). When spiders consumed the caffeinesoaked flies, they became disoriented and were unable to properly build their nests. It was also observed (Tiepo et al. 2010) that caffeine can be used against termites in tens of grams per kg of dry soil, while it does not have any effect on non-target organisms, such as earthworms, springtails, higher plants, and bacteria. After caffeine application, the termites were not killed, but subsequent communications in the community through pheromones were negatively affected (Tiepo et al. 2010). The ecotoxicity and genotoxicity of caffeine for aquatic organisms was not observed (Testolin et al. 2012). Pure caffeine (99\% purity) was also tested on organisms, such as algae, plant seeds, daphnia, and enchytraeids, and some effects were observed only for concentrations several orders of magnitude higher than those normally occurring in surface waters (Kobetičová et al. 2015).

The fungicidal effects of caffeine have been studied by several research groups in the past. Arora and Ohlan (1997) analyzed the effectiveness of tea extracts and pure caffeine against ten species of brown-rot and white-rot fungi in screening tests. Lekounougou et al. (2007) tested caffeine against three brown-rot and two white-rot fungi, but only in a combination with commercial propiconazole. Ratajczak et al. (2018) investigated the effect of caffeine in combination with organosilanes on impregnated wood, but using only one concentration. Kwasniewska-Sip et al. $(2018,2019)$ studied the effects of caffeine on ten molds and four fungi species under several treatment conditions with varying success.

Caffeine can be degraded to its natural metabolites theophylline and theobromine. Both these substances are quite common in human life. Theophylline is used, e.g., in therapy for respiratory diseases, while both theobromine and theophylline are present in tea and cocoa. However, their effects against wood-destroying pests have not been studied yet, contrary to caffeine.

In this study, the sensitivity of four fungal species to caffeine and its two metabolites theophylline and theobromine is investigated using in vitro tests under laboratory conditions. The methylxanthines used in the study possessed a similar chemical formula. In particular, the variant presence/absence or position of function groups may affect their toxicity to organisms. Therefore, the bioassays aimed at the identification of the effects of caffeine, theophylline, and theobromine on the wood-destroying fungi are performed on agar, excluding their possible interactions with wood materials. Degradation of studied methylxanthines were analyzed as well and the toxicological data were correlated to their properties.

\section{EXPERIMENTAL}

\section{Materials}

Chemicals

Caffeine $\left(\mathrm{C}_{8} \mathrm{H}_{10} \mathrm{~N}_{4} \mathrm{O}_{2}\right)$, theobromine $\left(\mathrm{C}_{7} \mathrm{H}_{8} \mathrm{~N}_{4} \mathrm{O}_{2}\right)$, and theophylline $\left(\mathrm{C}_{7} \mathrm{H}_{8} \mathrm{~N}_{4} \mathrm{O}_{2}\right)$ were purchased from Sigma-Aldrich (Prague, Czech Republic). Maltose agar was purchased from P-Lab (Pardubice, Czech Republic). Deionized (DI) water was used as a solvent for the preparation of methylxanthine solutions and agars. Water stock solutions were prepared up to the solubility limits at $20^{\circ} \mathrm{C}$ (caffeine $20 \mathrm{~g} / \mathrm{L}$, theobromine $0.33 \mathrm{~g} / \mathrm{L}$, 
and theophylline $5.5 \mathrm{~g} / \mathrm{L}$ ). The concentration scale for the tested substances was chosen according to the results of previous experiments: Caffeine - $0.125,0.250,0.5,1,2,5,10$, 15 , and $20 \mathrm{~g} / \mathrm{L}$; theobromine $-0.021,0.042,0.0825,0.165$, and $0.330 \mathrm{~g} / \mathrm{L}$; theophylline $0.125,0.250,0.5,1,2$, and $5.5 \mathrm{~g} / \mathrm{L}$ (Kobetičová et al. 2019).

\section{Test species}

Serpula lacrymans (Schumacher ex Fries), Karsten (strain BAM Ebw. 315), Coniophora puteana (Schumacher ex Fries), Karsten (strain BAM Ebw. 15), Gleophyllum sepiarium (Wulfen) Karsten (strain BAM Ebw. 873), and Trametes versicolor (Linnaeus ex Freis) Pilat (strain CBS 347.63) were used as model species. They were purchased from Timber Institute Ltd. (Prague, Czech Republic), except for T. versicolor, which was donated by the Mycological Department of Technical University of Zvolen (Faculty of Wood Science and Technology, Zvolen, Slovakia).

\section{Growth tests}

Tests were performed using the following setup. A $3 \%(\mathrm{w} / \mathrm{w})$ solution of test substance was prepared by dissolving the required amount in boiling DI water. It was then mixed with maltose agar. The mixture was poured into sterile glass Petri dishes. Three replicates were used for control (pure agar) and all tested substances and concentrations. Approximately $1.0 \mathrm{~cm}^{2}$ area of agar covered by fungi hyphae was transferred on the solidified agars. The agar dishes were covered with aluminum foil and stored in a biological chamber under dark with controlled temperature. The specific test conditions were selected on the basis of previous experiments and information obtained from the standard CSN EN 113 (2004). The temperatures corresponded to the optimal growth conditions of the particular species; for $S$. lacrymans and C. puteana $20^{\circ} \mathrm{C}$, G. sepiarium $27{ }^{\circ} \mathrm{C}$, and $T$. versicolor $35^{\circ} \mathrm{C}$. The evaluation of the tests was performed after 28 days of substance exposure.

\section{Chemical analyses}

Titration methods were used for the quantification of methylxanthines. Titration was preferred before other instrumental methods because of the high methylxanthines concentrations (from $\mathrm{mg}$ to $\mathrm{g}$ range). A stock solution of $3 \times 50 \mathrm{~mL}$ of each tested substance was prepared. The volumetric flasks containing solutions were kept in thermostats with temperatures corresponding to the test conditions $\left(20,27\right.$, and $\left.35^{\circ} \mathrm{C}\right)$. The titration was performed using a glass burette with $0.1-\mathrm{mL}$ graduation scale. The analysis was specific for each analyzed methylxanthine (Pharmacopoeia 2018a,b; Kobetičová et al. 2019).

\section{Equations}

Percentage-biomass coverage of agars affected by methylxanthines and controls without caffeine was analyzed by image analysis (NIS Elements, BR version 2.3, Prague, Czech Republic. The areas of plain agar medium and agar overgrown by fungi (in $\mathrm{cm}^{2}$ ) were marked for each Petri dish. The mean value was calculated for each concentration and control group. The inhibition of growth (in \%) was calculated according to the Eq. 1,

$$
I=100((C-S) / C)
$$

where $I$ is the inhibition of growth (\%), $C$ is the growth of fungi (\%) on control medium (agar without caffeine), and $S$ is the growth of fungi (\%) on caffeine affected medium (agar with various concentrations of caffeine). 
The growth values of each test species were compared (control vs. the tested concentrations) and subjected to a non-parametric analysis of variance (ANOVA) using GraphPad software (GraphPad Company, version 3, San Diego, CA, USA) and the Kruskal-Wallis test. The multiple comparison tests were performed at 0.05 significance levels. The coefficient of determination and linear regression were utilized to define the relationship between toxicity (mode $E C_{100}$ values) and selected properties (dipole moment, lipophilicity, electrophilicity, energy gap, and solubility in water) of studied methylxanthines. The $E C_{100}$ values corresponded to $100 \%$ inhibition of fungal growth and their mode values were selected for statistical analyses for more relevancy than mean values in this study.

\section{RESULTS AND DISCUSSION}

\section{Sensitivity of Fungi to Methylxanthines}

Figure 1 shows the growth of fungi on agar after 28-days of exposure to caffeine. Caffeine was tested in the concentration range of 0.125 to $20 \mathrm{~g} / \mathrm{L}$. For the concentrations of $2 \mathrm{~g} / \mathrm{L}$ and higher, a total inhibition of growth was observed for all fungal species. The least sensitivity was related to $T$. versicolor.

Theophylline (Fig. 2) caused some growth inhibition as well but the sensitivity of each fungus species to this substance was different. Contrary to caffeine, the most sensitive species was T. versicolor, followed by S. lacrymans, G. sepiarium, and the least sensitivity was related to $C$. puteana. Theobromine did not exhibit any effect on the growth of the representative fungal species (Fig. 3).

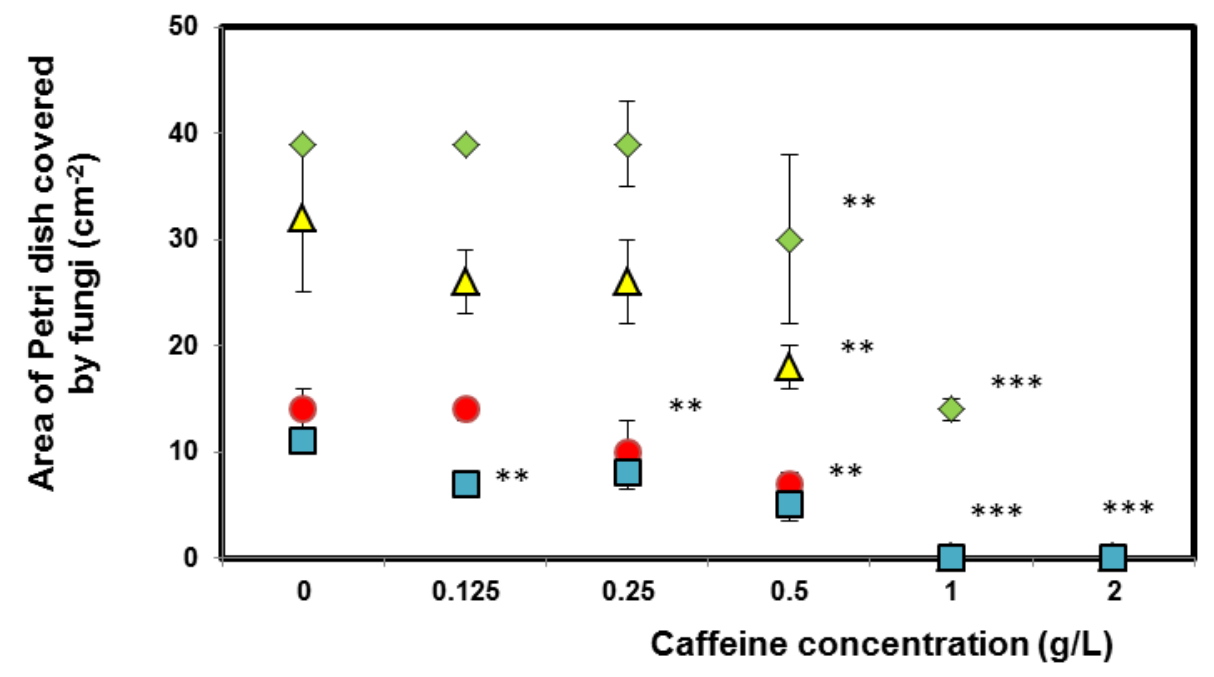

$\diamond T$. versicolor $\bullet$ G. sepiarium $\triangle$ C. puteana $\square$ S. lacrymans

Fig. 1. Growth of fungi T. versicolor, G. sepiarium, C. puteana, and S. lacrymans on agar with caffeine $(0.125,0.25,0.5,1$, and $2 \mathrm{~g} / \mathrm{L})$ after 28 days of exposure. Error bars represent the standard deviations. Asterisks represent statistically significant differences, the increasing number of asterisks corresponds to the increasing statistically significant differences $(n=3$, ANOVA, nonparametric Kruskal-Wallis test, $\mathrm{P}>0.05$ significance level). 


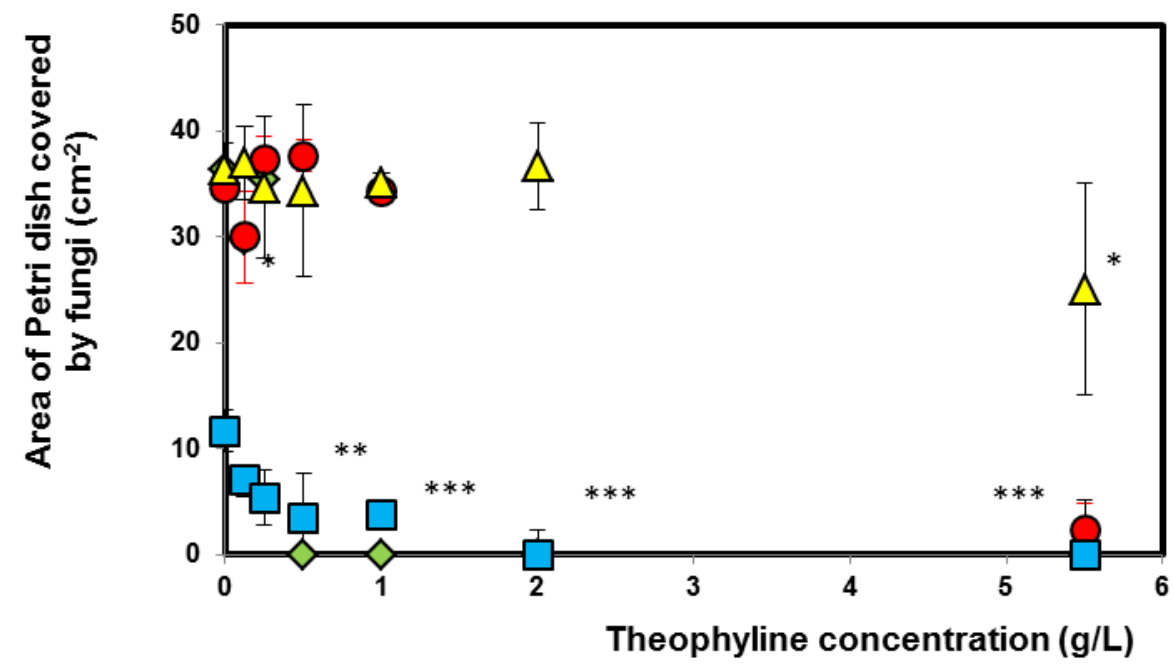

$\diamond$ T.versicolor $\bullet$ G. sepiarium $\triangle$ C.puteana $\quad$ S. lacrymans

Fig. 2. Growth of fungi T. versicolor, G. sepiarium, C. puteana, and S. lacrymans on agar with theophylline $(0.125,0.250,0.5,1,2$, and $5.5 \mathrm{~g} / \mathrm{L})$ after 28 days of exposure. Error bars represent the standard deviations. Asterisks represent statistically significant differences, the increasing number of asterisks corresponds to the increasing statistically significant differences $(n=3$, ANOVA, nonparametric Kruskal-Wallis test, $\mathrm{P}>0.05$ significance level).

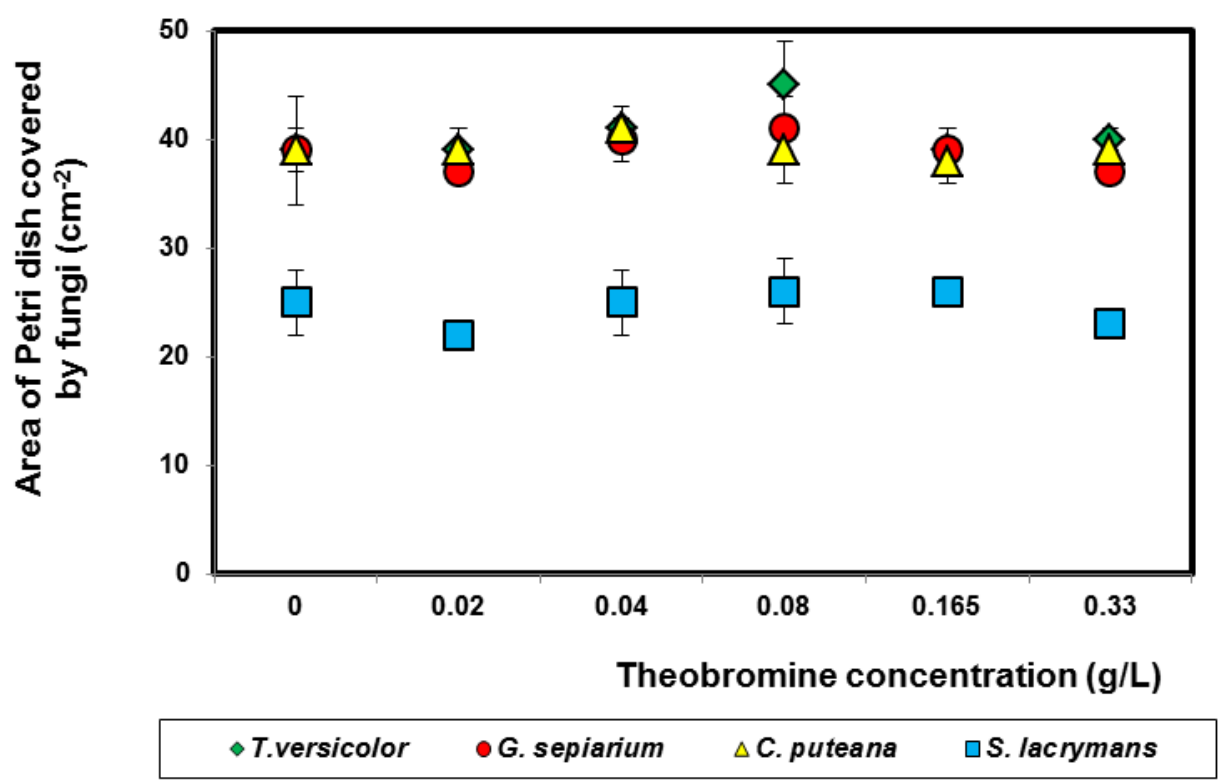

Fig. 3. Growth of fungi T. versicolor, G. sepiarium, C. puteana, and S. lacrymans on agar with theobromine $(0.02,0.04,0.08,0.165$, and $0.33 \mathrm{~g} / \mathrm{L})$ after 28 days of exposure. Error bars represent the standard deviations $(n=3$, ANOVA, nonparametric Kruskal-Wallis test, $P=0.05$ significance level). Comparison of control values (0) with the tested concentrations did not indicate statistically significant differences for all model species.

T. versicolor species is representative of white-rot fungi that can degrade not only lignin but also cellulose and hemicellulose. Therefore, some lignivorous fungi can possibly be less sensitive to caffeine because of their feeding preferences. This hypothesis is based on the general presumption that lignin is a variable polyphenolic amorphous substance 
without a regular periodic structure. It is possible that caffeine can interact with lignin containing unknown chemical components, which can protect fungi against the caffeine bioavailability and the following accessibility.

The fungal growth inhibiting capabilities of caffeine, which were shown in this study, were in a good qualitative agreement with Lekounougou et al. (2007), who analyzed the effects of caffeine on fungal growth and reported a complete growth inhibition of five species of wood decaying fungi. Kwasnievska-Sip et al. (2018) found four species of wood destroying fungi to be sensitive to caffeine application at concentrations $10 \mathrm{~g} / \mathrm{L}$ or higher. Clearly, the sensitivity of fungi in the present study was higher than that in KwasnievskaSip et al. (2018), which was due to the use of agar substrate avoiding possible interactions with wood. The results obtained for theophylline and theobromine in this paper could not be compared with any previous investigations, as such research was not reported yet in common literature sources.

Table 1 shows that caffeine and theobromine did not degrade significantly in the sterile environment during the time period of 28 days. Moreover, there was not any significant difference between the results obtained for the individual substances and temperatures. Theophylline was degraded more intensively, up to $34 \%$. Unfortunately, research studies dealing with environmental degradation of methylxanthines are lacking in common literature sources. Most of the previously published papers were focused on monitoring, disposable effects, or removal of caffeine from natural waters (e.g., Costa et al. 2019; Lomba et al. 2019; De Oliveira et al. 2019), not on the time development of methylxanthines' degradation in a specific medium. Therefore, any comparison of data obtained in this study with results presented by other investigators could not be done.

Table 1. Concentration of Caffeine, Theophylline, and Theobromine After 0, 14, and 28 Days at 20,27 , and $35^{\circ} \mathrm{C}$, as Determined by Titration Method

\begin{tabular}{|c|c|c|c|c|}
\hline \multirow[b]{2}{*}{ Substance } & \multirow[t]{2}{*}{ Temperature } & $20^{\circ} \mathrm{C}$ & $27^{\circ} \mathrm{C}$ & $35^{\circ} \mathrm{C}$ \\
\hline & & $0 / 14 / 28$ days & 0/14/28 days & $0 / 14 / 28$ days \\
\hline Caffeine & \multirow{3}{*}{$\begin{array}{c}\text { Concentration } \\
(\mathbf{g} / \mathbf{L})\end{array}$} & $20 / 18.3 / 18.3$ & $16.7 / 20 / 20$ & $18.3 / 18.3 / 20$ \\
\hline Theophylline & & $5.5 / 4.7 / 3.6$ & $4.1 / 3.6 / 3.6$ & $4.0 / 3.6 / 3.6$ \\
\hline Theobromine & & $0.3 / 0.3 / 0.3$ & $0.3 / 0.3 / 0.3$ & $0.3 / 0.3 / 0.3$ \\
\hline
\end{tabular}

\section{Relation of Toxicity to Chemical, Physical, and Theoretical Properties of Methylxanthines}

The observed sensitivity of fungi to studied methylxanthines can be explained by the differences in their chemical, physical, and theoretical properties. Caffeine contains three methyl groups in its structure, contrary to theophylline and theobromine. The functional methyl group in position one is present in caffeine and theophylline, not in theobromine; this might be one of the factors causing the inability of theobromine to stop the growth of fungi. Theobromine with its amide type linkage (containing $-\mathrm{N}-\mathrm{H}$ group) is a hydrogen donor and has basic as well acid properties. This is different from theophylline and caffeine, which are weak Brönsted bases (Salihovic et al. 2014). Theobromine is also the most polar compound according to its electrical dipole moment (Table 2). It is related to the polarity of the molecule and the distribution of the charge. Dipole moment seems to be the most important parameter characterizing the toxicity of studied methylxanthines for fungi (Table 3, Fig. 4). 
Table 2. Selected Properties of Caffeine, Theophylline, and Theobromine

\begin{tabular}{|c|c|c|c|c|}
\hline Property & Caffeine & Theophylline & Theobromine & Source \\
\hline Scheme of Molecule & & & & $\begin{array}{l}\text { PubChem 2020a, } \\
\text { 2020b, and 2020c }\end{array}$ \\
\hline $\begin{array}{l}\text { Toxicity }(\mathrm{g} / \mathrm{L}) \text { : } \\
\text { Mode } E C_{100}\end{array}$ & 1 & 2 & $>0.33$ & Present study \\
\hline $\begin{array}{c}\text { Solubility in Water } \\
(\mathrm{g} / \mathrm{L})\end{array}$ & $20.00^{a}$ & $5.50^{b}$ & $0.33^{c}$ & $\begin{array}{l}\text { PubChem 2020a, } \\
2020 b \text {, and 2020c }\end{array}$ \\
\hline $\begin{array}{c}\text { Lipophilicity - Kow } \\
\text { (Log) }\end{array}$ & -0.77 & -0.22 & -0.22 & Salihovic et al. 2014 \\
\hline Dipole Moment & 3.80 & 3.51 & 4.30 & Salihovic et al. 2014 \\
\hline Energy Gap ( $\Delta)$ & 5.12 & 5.14 & 5.13 & Salihovic et al. 2014 \\
\hline Electrophilicity (eV) & 2.27 & 2.41 & 2.37 & Salihovic et al. 2014 \\
\hline $\begin{array}{c}\text { Chemical Potential } \\
(\mathrm{eV})\end{array}$ & -3.41 & -3.52 & -3.49 & Salihovic et al. 2014 \\
\hline
\end{tabular}

Table 3. Relations Between Log of Mode $E C_{100}$ Values Obtained From the Toxicity Values of Tested Substances for All Studied Fungi and Selected Properties

\begin{tabular}{|c|c|c|}
\hline Property & Equation of Linear Regression & Deterministic Coefficient $\left(\mathbf{R}^{\mathbf{2}}\right)$ \\
\hline Dipole Moment & $\mathrm{y}=0.39 \mathrm{x}+2.16$ & $\mathbf{0 . 9 8}$ \\
\hline Log Kow & $\mathrm{y}=-1.15 \mathrm{x}+40.20$ & $\mathbf{0 . 8 6}$ \\
\hline Solubility in Water & $\mathrm{y}=0.33 \mathrm{x}-23.14$ & 0.58 \\
\hline Electrophilicity & $\mathrm{y}=-4.5 \mathrm{x}+162.00$ & 0.02 \\
\hline Chemical Potential & $\mathrm{y}=-0.93 \mathrm{x}-328.27$ & 0.02 \\
\hline
\end{tabular}

Log values from the Table 2, expressed by linear regression curves and deterministic coefficients $\left(\mathrm{R}^{2}\right)$

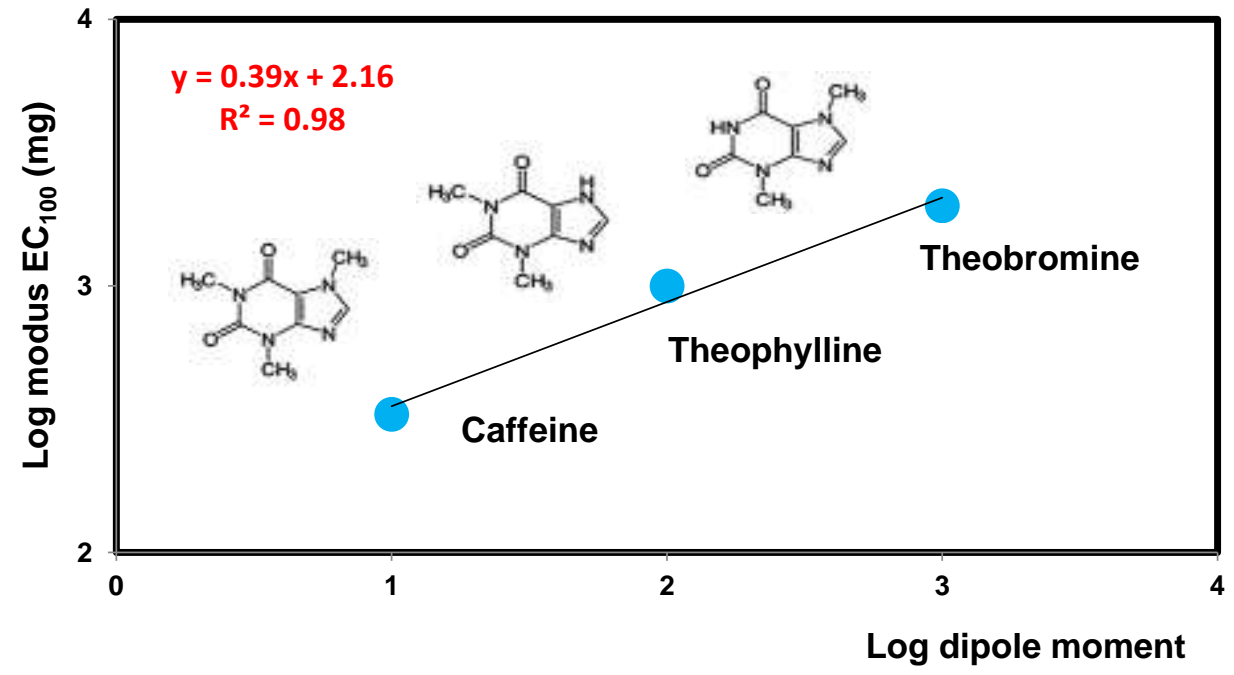

Fig. 4. Model of linear regression between log of mode $E C_{100}$ estimates from the toxicity values of tested substances for all studied fungi and dipole moment with its the deterministic coefficient $\left(R^{2}\right)$ 
Caffeine has a methyl group in position 7 that it cannot donate protons, contrary to theophylline, which can donate protons from position 7 (Salihovic et al. 2014). Electrophilicity indicates the capacity of a substance to accept electrons (SpirtovicHalilovic et al. 2013), but this property did not significantly impact the results (Table 3). In contrast, caffeine is the most lipophilic among the tested substances. This property, expressed as $\log \mathrm{Kow}$, is correlated with its easier penetration through membranes and possible toxic effects as described in the previous studies (Hecht et al. 1992; Kobetičová et al. 2011). It appears that this property can explain best the antifungal effects of caffeine in the present study (Fig. 1, Table 3).

Solubility in water is another parameter affecting the toxicity. It is generally known that the amount in excess of the solubility limit does not further contribute to the toxic effect. The tested substances indicated certain order-of-magnitude differences in solubility, ranging from $0.33 \mathrm{~g} / \mathrm{L}$ to $20 \mathrm{~g} / \mathrm{L}$ and higher toxicity corresponded with higher solubility (Figs. 1, 2, and 3).

Some previous studies (Rao et al. 2005; Tsilirakis et al. 2012) showed that caffeine affects the biological cycle of chitin polymer. This polymer is a polysaccharide composed of $\mathrm{N}$-acetyl-D-glucosamine molecules linked by 1,4- $\beta$-glycosidic bonds (Duo-Chuan 2006; Gortari and Hours 2008), which also forms a part of fungal cell walls (Tharanathan and Kittur 2003). Rao et al. (2005) described the same mode of action of caffeine and theophylline as inhibitors of chitinases (enzymes) through bonding on the non-reducing end of the glycosidic bonds. According to their model, the xanthine rings can create hydrogen bonds with chitinases. In addition, Rao et al. (2005) found that caffeine was more toxic than theophylline, which was in a qualitative agreement with the results of this study. Unfortunately, Rao et al. (2005) did not test theobromine. Therefore, a complete comparison of the authors' results with their findings on the mode of action and toxicity could not be done.

The lower toxicity of theophylline can be further explained by its more rapid degradation, when compared to caffeine (Table 1, Table 3). In general, the values of coefficients of determination $\left(\mathrm{R}^{2}\right)$ indicated that the dipole moment was probably the most important factor affecting the antifungal activity of methylxanthines, followed by lipophilicity and partly solubility in water as properties of potential toxicity and antifungal effects.

\section{CONCLUSIONS}

1. The growth inhibition effects of three methylxanthines (caffeine, theobromine, and theophylline) on four wood-destroying fungi (Serpula lacrymans, Coniophora puteana, Gleophyllum sepiarium, and Trametes versicolor) were analyzed by in vitro tests. The basic tests were complemented by the investigation of degradability of applied methylxanthines. The experiments were performed on agar medium at defined laboratory conditions for 28 days.

2. The dipole moment and lipophilicity were identified as important parameters affecting the antifungal properties of studied methylxanthines.

3. The analyzed wood-destroying fungi belong to the most dangerous species for the wood construction industry. In this paper, theobromine did not affect the growth of fungal species. Caffeine and theophylline were demonstrated as effective natural 
substances inhibiting their growth. However, as theophylline was subject to rapid degradation (36\%), caffeine could be considered as the most suitable antifungal substance. This finding can be utilized well in many wood applications in the building sector.

\section{ACKNOWLEDGMENTS}

This research has been supported by the Czech Science Foundation under Project No. 19-02067S.

\section{REFERENCES CITED}

Arora, D. S., and Ohlan, D. (1997). "In vitro studies on antifungal activity of tea (Camellia sinensis) and coffee (Coffea arabica) against wood-rotting fungi," J. Basic Microbiol. 37, 159-165. DOI: 10.1002/jobm.3620370302

Ashihara, H., Sano, H., and Crozier, A. (2008). "Caffeine and related purine alkaloids: Biosynthesis, catabolism, function and genetic engineering," Phytochemistry 69, 841856. DOI: 10.1016/j.phytochem.2007.10.029

Costa, I. L., Machado, C. S., Pletsch, A. L., and Torres, Y. R. (2019). "Simultaneous HPLC-PDA determination of commonly prescribed antidepressants and caffeine in sludge from sewage treatment plants and river sediments in the Itaipu reservoir region, Parana, Brazil,” Int. J. Environ. Anal. Chem. 100(9), 1004-1020. DOI: 10.1080/03067319.2019.1646738

CSN EN 113 (2004). "Wood preservatives - Test method for determining the protective effectiveness against wood destroying basidiomycetes - Determination of the toxic values," Czech Office for Standards, Metrology and Testing, Prague, Czech Republic.

De Oliveira, M., Atalla, A. A., Farias, F., Breno, E., Cavalheri, P. S., Migliolo, L., Magalhaes, F., and Fernando, J. C. (2019). "Ibuprofen and caffeine removal in vertical flow and free-floating macrophyte constructed wetlands with Heliconia rostrata and Eichornia crassipes," Chem. Engin. J. 373, 458-467. DOI: 10.1016/j.cej.2019.05.064

Duo-Chuan, L. (2006). "Review of fungal chitinases," Mycopathologia 161, 345-360. DOI: $10.1007 / \mathrm{s} 11046-006-0024-\mathrm{y}$

Gortari, M., and Hours, R. A. (2008). "Fungal chitinases and their biological role in the antagonism onto nematode eggs, a review," Mycol. Prog. 7(4), 221-238. DOI: 10.1007/s11557-008-0571-3

Hecht, P., Vyplel, H., Nussbaumer, P., and Berner, H. (1992). "A combined use of quantum chemical parameters, hydrophobic and geometrical descriptors to establish QSARS of allylamine antimycotics," Quant. Struct.-Act. Relat. 11(3), 339-347. DOI: 10.1002/qsar.2660110306

Hesselberg, T., and Vollrath, F. (2004). "The effects of neurotoxins on web-geometry and web-building behaviour in Araneus diadematus," Physiol. Behav. 82(2-3), 519- 529. DOI: 10.1016/j.physbeh.2004.04.058

Islam, M. S., Hamdan, S., Hasan, M., Ahmed, A. S., and Rahman, M. R. (2012). "Effect of coupling reactions on the mechanical and biological properties of tropical wood 
polymer composites (WPC)," Int. Biodeter. Biodegrad. 72, 108-113. DOI:

10.1016/j.ibiod.2012.05.019

Kobetičová, K., Šimek, Z., Brezovsky, J., and Hofman, J. (2011). “Toxic effects of nine polycyclic aromatic compounds on Enchytraeus crypticus in artificial soil in relation to their properties," Ecotoxicol. Environ. Saf. 74(6), 1727-1733. DOI:

10.1016/j.ecoenv.2011.04.013

Kobetičová, K., Losonszky, G., Pařízek, O., and Kočí, V. (2015). "Effects of caffeine on plants," in: Proceedings of the Conference Influence of Abiotic and Biotic Stresses on Properties of Plants, Prague, Czech Republic, pp. 166-168.

Kobetičová, K., Ďurišová, K., Petř́ková, M., Nábělková, J., and Černý, R. (2019).

"Titration methods of methylxanthines," in: Conference Proceedings of $7^{\text {th }}$

International Conference on Chemical Technology in Mikulov 2019, Mikulov, Czech Republic, pp. 310-313.

Kobetičová, K., Kočí, V., Petř́ḱková, M., Šimůnková, K., and Černý, R. (2019). “Growth effectivity of molds in contact with methylxanthines," in: Conference Proceedings of $4^{\text {th }}$ Central European Symposium on Building Physics 2019, Prague, Czech Republic, 02058.

Kwasniewska-Sip, P., Cofta, G., and Nowak, P. B. (2018). "Resistance of fungal growth on Scots pine treated with caffeine," Int. Biodeterior. Biodegrad. 132, 178-184. DOI: 10.1016/j.ibiod.2018.03.007

Kwasniewska-Sip, P., Bartkowiak, M., Cofta, G., and Nowak, P. B. (2019). "Resistance of Scots pine (Pinus sylvestris L.) after treatment with caffeine and thermal modification against Aspergillus niger," BioResources 14(1), 1890-1898. DOI: 10.15376/biores.14.1.1890-1898

Lekounougou, S., Ondo, J. P., Jacquot, J., Nevers, G., Gérardin, P., and Gelhaye, E. (2007). "Effects of caffeine on growth of wood-decaying fungi," in: International Research Group on Wood Protection, Stockholm, Sweden, IRG/WP 07-30427.

Lomba, L., Pilar, R. M., Zuriaga, E., Garcia, C. B., and Giner, B. (2019). “Acute and subacute effects of drugs in embryos of Danio rerio. QSAR grouping and modelling," Ecotoxicol. Environ. Saf. 172, 232-239. DOI: 10.1016/j.ecoenv.2019.01.081

Pharmacopoeia (2018a). "Theophyllinum," (http://www.lekopis.cz/Kap_6_1_Theophyllinum.htm), Accessed 01 July 2020.

Pharmacopoeia (2018b). "Theobrominum," (http://www.lekopis.cz/Kap_6_1_Theobrominum.htm), Accessed 01 July 2020.

PubChem (2020a). "Caffeine,"

(https://pubchem.ncbi.nlm.nih.gov/compound/Caffeine), Accessed 01 July 2020.

PubChem (2020b). "Theophylline," (https://pubchem.ncbi.nlm.nih.gov/compound/Theophylline), Accessed 01 July 2020.

PubChem (2020c). "National Library of medicine," Available at (https://pubchem.ncbi.nlm.nih.gov/compound/Theobromine), Accessed 01 July 2020.

Rahman, N. A. A., Muharram, S. H, and Abiola, O. (2014). "Antibacterial activity of NESCAFÉ instant coffee beverages and pharyngitis-causing Streptococcus species," Brunei Darussalam Journal of Health 5, 70-79.

Rao, F. V., Andersen, O. A., Vora, K. A., Demartino, J. A., and Van Aalten, D. M. (2005). "Methylxanthine drugs are chitinase inhibitors: Investigation of inhibition and binding modes," Chem. Biol. 12(9), 973-980. DOI: 10.1016/j.chembiol.2005.07.009

Ratajczak, I., Wozniak, M., Kwasniewska-Sip, P., Szentner, K., Cofta, G., and Mazela, B. (2018). "Chemical characterization of wood treated with a formulation based on 
propolis, caffeine and organosilanes," Eur. J. Wood Wood Prod. 76, 775-781. DOI: 10.1007/s00107-017-1257-9

Salihovic, M., Huscinovič, Š., Spirtovic-Halilovic, S., Osmanovič, A., Dedič, A., Ašimovič, Z., and Završnik, D. (2014). "DFT study and biological activity of some methylxanthines," Bulletin of Chemists and Technologists of Bosnia and Herzegovina 42, 31-36.

Singh, T., and Singh, A. P. (2012). "A review on natural products as wood protectant," Wood Sci. Technol. 46, 851-870. DOI: 10.1007/s00226-011-0448-5

Spirtovic-Halilovic, S., Salihovic, M., Džudževic-Čančar, H., Trifunovic, S., Roca, S., Softic, D., and Završnik, D. (2013). "DFT study and microbiology of some coumarinbased compounds containing a chalcone moiety," J. Serb. Chem. Soc. 79(4), 435-443. DOI: $10.2298 . J S C 130628077 \mathrm{~S}$

Testolin, R. C., Tischer, V., Lima, A. O., Cotelle, S., Férard, J. F., and Radetski, C. M. (2012). "Aquatic ecotoxicity assessment of a new natural formicide," Environ. Sci. Pollut. Res. Int. 19(6), 2186-2194. DOI: 10.1007/s11356-011-0721-z

Tharanathan, R. N., and Kittur, F. S. (2003). "Chitin-The undisputed biomolecule of great potential," Crit. Rev. Food Sci. Nutr. 43(1), 61-87. DOI:

10.1080/10408690390826455

Thomas, R. C. (2013). "Calcium content of the endoplasmic reticulum of snail neurons releasable by caffeine," Cell Calcium 53(2), 120-124. DOI: 10.1016/j.ceca.2012.10.007

Tiepo, E. N., Correa, A. X. R., Resgalla, C., Jr., Cotelle, S., Ferard, J. F., and Radetski, C. M. (2010). "Terrestrial short-term ecotoxicity of a green formicide," Ecotoxic.

Environ. Saf. 73(5), 939-943. DOI: 10.1016/j.ecoenv.2010.01.009

Article submitted: June 28, 2020; Peer review completed: August 29, 2020; Revised version received and accepted: August 31, 2020; Published: September 7, 2020.

DOI: $10.15376 /$ biores.15.4.8110-8120 